\title{
EFFECT OF STANDARDIZED UPTAKE VALUE DISCRETIZATION ON RADIOMICS FEATURES OF LIVER TUMORS USING 18FDG-PET/CT SCAN
}

\author{
Mahmoud M.A. ${ }^{1}$, Shihab M. ${ }^{2}$, Saad SS. ${ }^{2}$, Elhussiny F.2, Houseni M. ${ }^{1}$ \\ 1 - Department of Radiology, National Liver Institute, Menoufia University, Shibin El-Koum, Egypt \\ 2 - Department of Physics, Faculty of science, Tanta University, Tanta, Egypt.
}

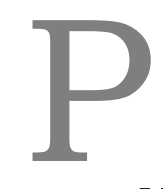

urpose. In this contribution, we study the dependence of radiomics features extracted from 18F- fluorodeoxyglucose - positron emission tomography/computed tomography (18F-FDG $\mathrm{PET} / \mathrm{CT}$ ) on different SUV discretization intensity values in patients with liver cancer type hepatocellular carcinoma (HCC).

Materials and methods. 35 radiomic features were extracted from PET images using semiautomatic method through 4 discretization intensity values with number of grey levels $=(32,64,128$, 256). Determination of bin within dour different. One way analysis of variance (ANOVA) was used to obtain whether there is significant difference between radiomics features at the four discretization values.

Results. By comparing the average and variance of radiomics through the four discretization values, only the first order skewness and kurtosis are stable through the different discretization values, where all the other features demonstrated significant difference between features in the 4 values. Spearman correlation coefficient between radiomics features and tumors parameters calculated.

Conclusion. The discretization level of 256 have been found to be the optimum discretization value to extract the radiomics features.

Keywords: FDG PET/CT, liver, radiomics, discretization.

Corresponding author: Menna Allah Mahmoud, e-mail: m.shehata@liver.menofia.edu.eg

For citation: Mahmoud M.A., Shihab M., Saad SS., Elhussiny F., Houseni M. Effect of standardized uptake value discretization on radiomics features of liver tumors using 18FDG-PET/CT scan. REJR 2021; 11(3):132-137. DOI: 10.21569/2222-7415-2021-11-3-132-137.

Received: $\quad$ 13.05.21 $\quad$ Accepted: $\quad 30.08 .21$

\section{ВАИЯНИЕ АИСКРЕТИЗАЦИИ СТАНААРТИЗИРОВАННОГО КОЭФФИЦИЕНТА НАКОПАЕНИЯ НА ОСОБЕННОСТИ РААИОМИКИ ОПУХОАЕЙ ПЕЧЕНИ С ИСПОАЬЗОВАНИЕМ 18FDG-ПЭТ/КТ-СКАНИРОВАНИЯ}

\author{
Mahmoud M.A. ${ }^{1}$, Shihab M.2, Saad SS.2, Elhussiny F.2, Houseni M.' ${ }^{1}$
}

1 - Отделение радиологии, Национальный институт печени, Университет Менуфия, Шебин Эмь-Кум, Египет 2 - Факультет физики, Факультет естественньх наук, Университет Танта, Танта, Египет.

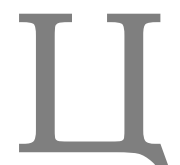

ель исследования. В этой статье мы изучаем зависимость радиомических характеристик, полученных с помощью $18 \mathrm{~F}$ - фтордезоксиглюкозо - позитронно-эмиссионной томографии/компьютерной томографии (18F-ФДГ ПЭТ/КТ), от разАичных значений интенсивности дискретизации SUV у пациентов с гепатоцелмюлярной карциномой типа рака печени (ГЦК).

Материалы и методы. 35 радиомических признаков были извлечены из изображений ПЭТ полуавтоматическим методом с помощью 4 значений интенсивности дискретизации с ко- 


\section{RUSSIAN ELECTRONIC JOURNAL OF RADIOLOGY}

мичеством уровней серого $=(32,64,128,256)$. Односторонний дисперсионный анализ (ANOVA) использовался для определения того, существует $\Lambda$ существенная разница между функциями радиомики при четырех значениях дискретизации.

Результаты. Сравнивая среднее значение и дисперсию радиомики по четырем значениям дискретизации, только асимметрия и эксцесс первого порядка являются стабимьными при различных значениях дискретизации, где все остальные признаки продемонстрировали значительную разницу между признаками в 4 значениях. Рассчитан коэффициент корреляции Спирмена между особенностями радиомики и параметрами опухолей.

Выводы. Бымо установлено, что уровень дискретизации 256 является оптимальным значением дискретизации для извцечения функций радиомики.

КАючевые слова: ФДГ ПЭТ/КТ, печень, радиомика, дискретизация.

Контактный автор: Menna Allah Mahmoud, e-mail: m.shehata@liver.menofia.edu.eg

Для иитирования: Mahmoud M.A., Shihab M, Saad SS., Elhussiny F., Houseni M. Bлияние дискретизаиии стандартизированного коэффиииента накопления на особенности радиомики опухолей печени с использованием 18FDG-ПЭT/KT-сканирования. REJR 2021; 11(3):132-137. DOI: 10.21569/2222-7415-2021-11-3-132-137.

\section{Статья получена: $\quad$ 13.05.21 $\quad$ Статья принята: $\quad 30.08 .21$}

\section{I}

\section{ntroduction.}

Positron emission tomography or "PET" scanning is the most known nuclear medicine test today. Most PET is based on a positron-emitting isotope of fluorine $(\mathrm{F}-18)$ that is incorporated into a glucose analog called fluorodeoxyglucose (FDG) as glucose uptake is higher in most cancers, the most used PET technique in oncology is FDG PET [1].

With many types of medical imaging, patients usually undergo a multiplicity imaging scans to correlate anatomic and functional details and make comparison from this different modality. Now a day, hybrid imaging is used which depending on combining two different techniques in one device like PET/CT and PET/MRI and many fusion images techniques were developed to better evaluating to patients diagnosis and treatment[2].

Imaging in cancer treatment and diagnosis has a great role and advantages as noninvasive techniques. Currently with medical imaging revolutions, cancer can be detect at early stages and treatment planning and assessment is possible.

One of the largest limitations to medical imaging in cancer diagnosis is that it depends on the naked eye which cannot cover all areas in the images and may be not accurate. So, radiomics which is a new area depending on extracting more information from medical imaging through high quantitative techniques have been invited for the first time by Lambin et al. 2012 and reviewed the previous works depending on similar ideas like texture analysis [3]

Radiomics showed a promise way to en- hance medical diagnosis, However, studies found that radiomics values are interchangeable through many factors like voxel size [4, 5], reconstruction algorithms [6, 7], tumor segmentation methods [8], and gray-level discretization [9].

SUV discretization (i.e. the resampling of image intensity values) is one important methodological aspect.

Discretization reduces the otherwise infinite number of intensity values to a finite range and reduces image noise effectively. The most discretization way is the use of a fixed number (e.g. 8, 16) of distinct resampled values or' bins' to divide the spectrum of the SUV image into equally spaced intervals before measuring textural characteristics. It leads to distinct images with different bin sizes or pressure resolutions,' depending on the SUV set. An alternative discretization approach is to resample the picture SUVs in SUV units with a set bin size e.g. 0.1, 0.5), maintaining a continuous resolution of tumor intensities across all photo [10].

Effect of SUV discretization ton PETradiomics have been studied in cervical cancer [6], nasopharyngeal carcinoma [8], and non-small cell lung cancer (NSCLC) [9]. But according to our knowledge, this is no work studied effect of SUV discretization on liver cancer which is the aim of this current work.

Materials and methods.

Patients.

A retrospective study included 33 patients with proven liver cancer in type hepatocellular carcinoma HCC (29 males and 4 females) with a 


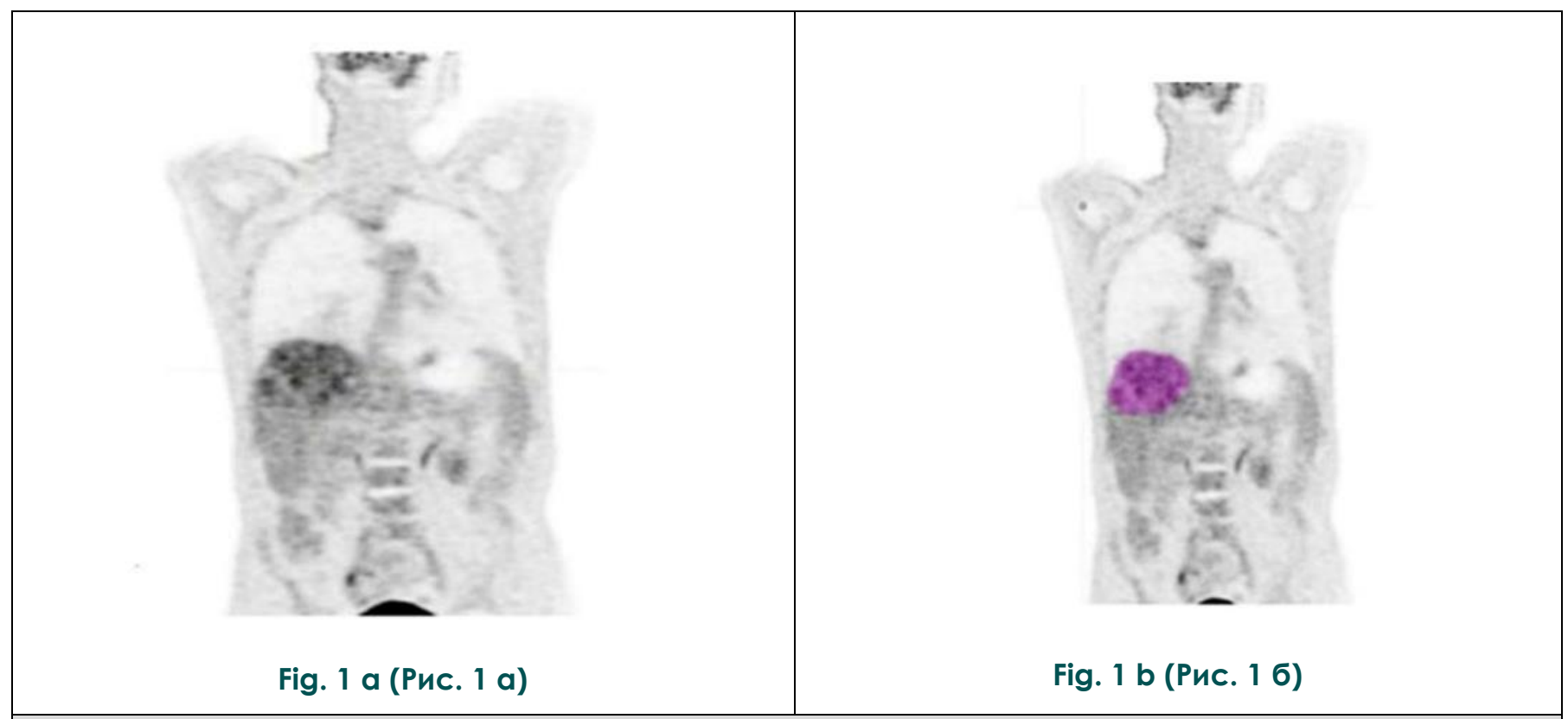

Fig. 1. PET scan before (a) and after (b) segmentation.

Patient, male, 74 у.о. HCC.

Рис. 1. ПЭТ-сканирование Ао (а) и после (б) сегментации.

Пациент, мужчина, 74 года, гцК.
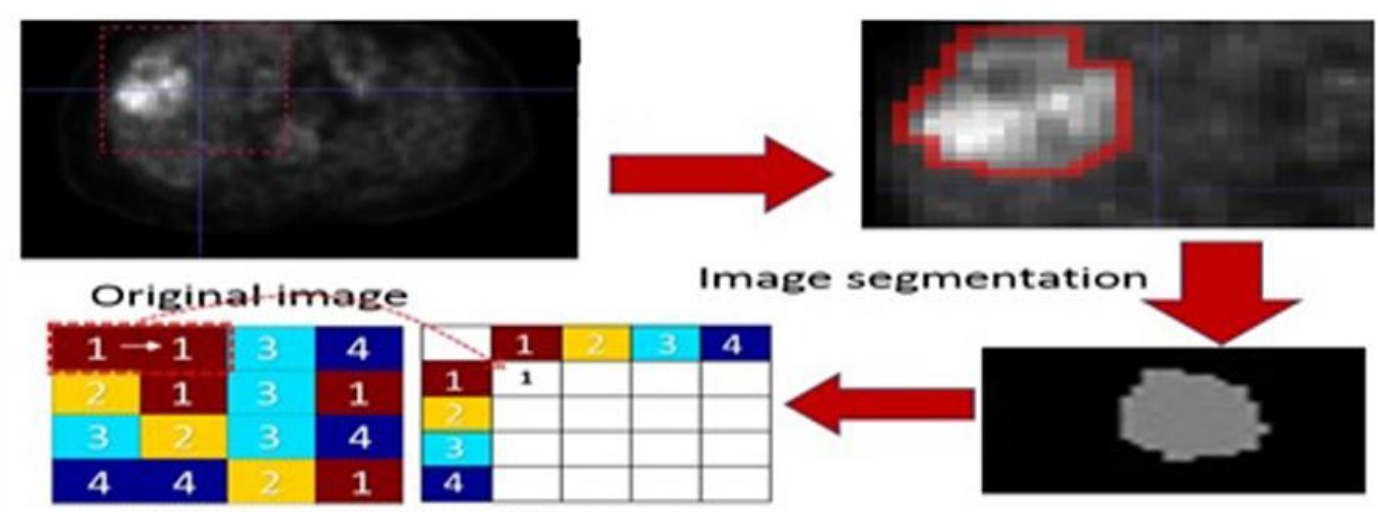

Image segmentation

Features extraction

Fig. 2 (Рис. 2)

\section{Fig. 2. The flow work of SUV parameters and radiomics features extraction.}

Рис. 2. Изображение потока параметров SUV и выАеление особенностей раАиомики.

range between 39-77 years. The study was approved the institutional review board (IRB), and informed consent was waived. of Average tumors maximum diameters $=7.85 \mathrm{~cm}$. Part of this patient data set was included in our previous study [13].

\section{Imaging techniques.}

The study performed using a PET/CT scanner model Siemens Biograph 128_mCT. The patients were positioned in the PET/CT scanner approximately after injection of FDG intravenously, the patients injected according to their weight by $0.1 \mathrm{mCi}$ or $3.7 \mathrm{MBq}$ for each $\mathrm{Kg}$. A non-contrast CT scan was acquired from the base of the skull to the upper thigh region and used for attenuation correction. Images size was $200 \times 200$ pixels and the slice thickness was $1 \mathrm{~mm}$.

Image processing and analysis.

The study with performed using a PET/CT scanner model Siemens Biograph 128_mCT. The patients were placed in the PET / CT scanner for approximately $0.1 \mathrm{mCi}$ or $3.7 \mathrm{MBq}$ per $\mathrm{kg}$ after 


\section{Table№2. F-value as calculated from one way ANOVA test for radiomics value, the blue cells are significantly different values.}

\begin{tabular}{|c|c|}
\hline Features & $\mathrm{F}$ \\
\hline HISTO_Skewness & $2.05577 \cdot 10-7$ \\
\hline HISTO_Kurtosis & $2.5025 \cdot 10-7$ \\
\hline HISTO_Entropy & 40.73428 \\
\hline HISTO_Energy & 47.58659 \\
\hline GLCM_Homogeneity & 93.41577 \\
\hline GLCM_Energy & 32.84599 \\
\hline GLCM_Contrast & 12.25819 \\
\hline GLCM_Correlation & 0.08647 \\
\hline GLCM_Entropy & 42.24817 \\
\hline Dissimilarity & 34.29993 \\
\hline GLRLM_SRE & 94.31666 \\
\hline GLRLM_LRE & 51.29019 \\
\hline GLRLM_LGRE & 69.79916 \\
\hline GLRLM_HGRE & 31.30058 \\
\hline GLRLM_SRLGE & 89.96654 \\
\hline GLRLM_SRHGE & 30.69235 \\
\hline GLRLM_LRLGE & 719.12887 \\
\hline GLRLM_LRHGE & 32.62331 \\
\hline GLRLM_GLNU & 22.01319 \\
\hline GLRLM_RLNU & 9.36432 \\
\hline GLRLM_RP & 39.77516 \\
\hline NGLDM_Coarseness & 0.00764 \\
\hline NGLDM_Contrast & 13.21109 \\
\hline NGLDM_Busyness & 19.89503 \\
\hline GLZLM_SZE & 101.5103 \\
\hline GLZLM_LZE & 12.31562 \\
\hline GLZLM_LGZE & 42.40519 \\
\hline GLZLM_HGZE & 29.91603 \\
\hline GLZLM_SZLGE & 23.44707 \\
\hline GLZLM_SZHGE & 22.59416 \\
\hline GLZLM_LZLGE & 7.04429 \\
\hline GLZLM_LZHGE & 9.41166 \\
\hline GLZLM_GLNU & 4.24986 \\
\hline GLZLM_ZLNU & 10.22901 \\
\hline GLZLM_ZP & 112.85751 \\
\hline
\end{tabular}

injection of FDG intravenously. A non-contrast CT scan from the base of the skull to the upper thigh region was obtained and used for correction of the attenuation. the PET scan segmented directly using a semiautomatic method in LIFEx package version 4.0.0 (https://www.lifexsoft.org), then 35 radiomics features calculated using LIFEX package. Fig1. Show a case of liver cancer before and after segmentation in LIFEx package.

\section{Radiomics features.}

The study used 35 radiomics features included: histogram indices, the gray level cooccurrence matrix (GLCM), the neighborhood gray-level different matrix (NGLDM), the gray-level run length matrix (GLRLM), the gray-level zone length matrix (GLZLM). Fig.2 show the workflow of radiomics extraction in this study. (https://lifexsoft.org/index.php/resources/19texture/radiomicfeatures?filter_tag [0]=).

Statistical analysis.

Radiomics features has been studied utilizing four discretization intensity values of gray levels, i.e., 32, 64, 128, and 256. One way of variance (ANOVA) used to determine the difference in features through the 4 discretization values.In order to determine the optimum discretization level to extract the radiomics features, a Spearman rank correlation coefficient between radiomics features and tumor parameters (metabolic tumor volume, total lesion glycolysis, Significance value in tests was 0.05 ,all statistical tests calculated and IBMSPSS version 19.

\section{Results.}

Radiomics features has been studied utilizing four discretization intensity values of gray levels, i.e., $32,64,128$, and 256 . One way of variance (ANOVA) used to determine the difference in features through the 4 discretization values as shown in table 1 .

According to F-Value determined from ANOVA which is the measurement of the differences of the groups means, four radiomics features only were stable through the different discretization values, where 31 features were statistically different as shown in table 1 .

\section{Discussion.}

Leijenaar et al. (2015) studied the effect of discretization of FDG-PET/CT lung cancer at values $8,16,32,64$ and 128 there results showed that the manner of SUV discretization can affect the interpretation of radiomics features [9].

Crandall et al. (2020) reported that GLCM, and NGLDM radiomic features were consistently stable while gray-level run length matrix (GLRLM) and gray-level zone length matrix (GLZLM) features were highly variable at discretization values 32, 64 and 128 in cervical cancer PET/ CT scan [12].

Fig. 3 shows plot of first order features vs. 


\begin{tabular}{|c|c|c|c|c|c|c|c|c|c|c|c|c|}
\hline Features/rs & $256 \mathrm{di}$ & $128 \mathrm{di}$ & $64 \mathrm{di}$ & $32 \mathrm{di}$ & 256 TLG & $128 \mathrm{TLG}$ & 64 TLG & 32 TLG & 256 MTV & 128 MTV & $64 \mathrm{MTV}$ & $32 \mathrm{MTV}$ \\
\hline HISTO_Skewness & 0.2506 & 0.2506 & 0.2506 & 0.2506 & 0.5053 & 0.5053 & 0.5053 & 0.5053 & 0.4271 & 0.4271 & 0.4271 & 0.4271 \\
\hline HISTO_Kurtosis & 0.2586 & 0.2586 & 0.2586 & 0.2586 & 0.1674 & 0.1674 & 0.1674 & 0.1674 & 0.2213 & 0.2213 & 0.2213 & 0.2213 \\
\hline HISTO_Entropy_Jog10 & 0.479 & 0.4805 & 0.45 & 0.4873 & 0.7517 & 0.7473 & 0.7463 & 0.7473 & 0.633 & 0.6283 & 0.627 & 0.6293 \\
\hline HISTO_Energy & -0.4552 & 0.4532 & 0.4323 & -0.4711 & -0.7447 & 0.7406 & 0.7316 & 0.7356 & -0.6203 & 0.6163 & 0.6063 & 0.6143 \\
\hline GLCM_Homogeneity & -0.2809 & -0.2824 & -0.2784 & .0 .2809 & -0.5826 & -0.5859 & -0.5922 & -0.5826 & 0.4251 & -0.4295 & 0.4378 & 0.4251 \\
\hline GLCM_Energy & -0.4192 & -0.439 & 0.409 & -0.4192 & -0.75 & 0.7356 & -0.7249 & 0.75 & -0.619 & 0.6023 & 0.5906 & -0.619 \\
\hline GLCM_Contrast & 0.3266 & 0.3224 & 0.3269 & 0.3266 & 0.631 & 0.6287 & 0.6287 & 0.631 & 0.483 & 0.4809 & 0.4773 & 0.483 \\
\hline GLCM_Correlation & 0.6225 & 0.6366 & 0.6277 & 0.6225 & 0.7807 & 0.7945 & 0.7988 & 0.7807 & 0.754 & 0.764 & 0.7614 & 0.754 \\
\hline GLCM_Entropy_logid & 0.4785 & 0.4525 & 0.4323 & 0.4785 & 0.8152 & 0.7584 & 0.7393 & 0.8152 & 0.6999 & 0.6327 & 0.6096 & 0.6999 \\
\hline Dissimilarity & 0.3174 & 0.3098 & 0.3145 & 0.3174 & 0.6257 & 0.6166 & 0.612 & 0.6257 & 0.4773 & 0.4679 & 0.4766 & 0.4773 \\
\hline GLRLM_SRE & 0.0258 & 0.0855 & 0.1169 & 0.0258 & 0.2821 & 0.3376 & 0.372 & 0.2821 & 0.1116 & 0.1651 & 0.2012 & 0.1116 \\
\hline GLRLM_LRE & 0.0549 & 0.0468 & 0.0875 & 0.0549 & 0.1176 & 0.2426 & 0.3011 & 0.1176 & -0.171 & 0.0695 & -0.131 & 0.0471 \\
\hline GLRLM_LGRE & -0.04 & -0.05 & -0.12 & -0.040 & -0.294 & 0.321 & 0.398 & -0.294 & -0.171 & -0.191 & -0.270 & 0.1715 \\
\hline GLRLM_HGRE & 0.3353 & 0.3286 & 0.346 & 0.3353 & 0.6761 & 0.6731 & 0.6862 & 0.6761 & 0.5261 & 0.5221 & 0.5394 & 0.5261 \\
\hline GLRLM_SRLGE & -0.042 & -0.086 & -0.152 & -0.04 & -0.308 & -0.382 & -0.449 & -0.308 & -0.185 & -0.256 & -0.318 & -0.185 \\
\hline GLRLM_SRHGE & 0.3353 & 0.3353 & 0.3314 & 0.3353 & 0.6631 & 0.6631 & 0.6578 & 0.6631 & 0.5127 & 0.5127 & 0.5124 & 0.5127 \\
\hline GLRLM_LRLGE & -0.014 & -0.019 & -0.008 & -0.014 & -0.231 & -0.236 & -0.209 & -0.231 & -0.104 & 0.104 & -0.074 & -0.104 \\
\hline GLRLM_LRHGE & 0.3649 & 0.3741 & 0.3883 & 0.3649 & 0.7189 & 0.7333 & 0.7624 & 0.7189 & 0.5735 & 0.5922 & 0.638 & 0.5735 \\
\hline GLRLM_GLNU & 0.6717 & 0.6829 & 0.6943 & 0.6717 & 0.7627 & 0.7797 & 0.8185 & 0.7627 & 0.8506 & 0.8643 & 0.893 & 0.8506 \\
\hline GLRLM_RLNU & 0.7341 & 0.7302 & 0.7143 & 0.7341 & 0.9886 & 0.9916 & 0.9947 & 0.9886 & 0.9853 & 0.9823 & 0.9733 & 0.9853 \\
\hline GLRLM_RP & 0.0104 & 0.0897 & 0.1074 & 0.0104 & 0.243 & 0.3342 & 0.3603 & 0.243 & 0.0665 & 0.1578 & 0.1852 & 0.0665 \\
\hline NGLDM_Coarseness & 0.7153 & 0.7137 & 0.711 & 0.7153 & 0.9572 & 0.9539 & 0.9489 & -0.9572 & -0.9676 & -0.9682 & 0.9652 & 0.9676 \\
\hline NGLDM_Contrast & 0.0736 & 0.0875 & 0.0054 & 0.0736 & 0.2911 & 0.3178 & 0.3132 & 0.2911 & 0.1283 & 0.1581 & 0.0896 & 0.1283 \\
\hline NGLDM_Busyness & 0.2561 & 0.6283 & 0.3418 & 0.2561 & 0.2503 & 0.3359 & 0.3506 & 0.2503 & 0.3981 & 0.4749 & 0.4676 & 0.3981 \\
\hline GLZLM_SZE & 0.123 & 0.2744 & 0.3018 & 0.123 & 0.3138 & 0.4736 & 0.381 & 0.3138 & 0.1678 & 0.3483 & 0.2811 & 0.1678 \\
\hline GLZLM_LZE & 0.1782 & 0.0974 & 0.1057 & 0.1782 & 0.0047 & .0 .1233 & .0 .0531 & 0.0047 & 0.1681 & 0.0652 & 0.1407 & 0.1681 \\
\hline GLZLM_LGZE & -0.225 & -0.3 & -0.311 & -0.225 & 0.5521 & -0.6173 & 0.5983 & 0.5521 & 0.3497 & 0.485 & 0.5043 & 0.4104 \\
\hline GLZLM_HGZE & 0.3483 & 0.3752 & 0.4122 & 0.3483 & 0.6822 & 0.7126 & 0.7256 & 0.6822 & 0.5368 & 0.5752 & 0.6243 & 0.5368 \\
\hline GLZLM_SZLGE & -0.2928 & 0.2792 & 0.3756 & .0 .2928 & -0.5993 & -0.6056 & -0.6604 & -0.5993 & 0.4973 & 0.507 & 0.6233 & 0.4973 \\
\hline GLZLM_SZHGE & 0.314 & 0.3644 & 0.4042 & 0.314 & 0.64 & 0.6908 & 0.6895 & 0.64 & 0.4903 & 0.5505 & 0.5929 & 0.4903 \\
\hline GLZLM_LZLGE & 0.1191 & 0.1593 & 0.191 & 0.1191 & 0.0077 & 0.004 & 0.0468 & 0.0077 & 0.1521 & 0.1721 & 0.2176 & 0.1521 \\
\hline GLZLM_LZHGE & 0.305 & 0.2387 & 0.1793 & 0.305 & 0.382 & 0.1123 & 0.1116 & 0.382 & 0.4459 & 0.246 & 0.2654 & 0.4459 \\
\hline GLZLM_GLNU & 0.675 & 0.7025 & 0.659 & 0.675 & 0.8924 & 0.9709 & 0.9773 & 0.8924 & 0.9365 & 0.9619 & 0.9181 & 0.9365 \\
\hline GLZLM_ZLNU & 0.6864 & 0.6695 & 0.6412 & 0.6864 & 0.9749 & 0.9529 & 0.9452 & 0.9749 & 0.9198 & 0.883 & 0.859 & 0.9198 \\
\hline GLZLM_ZP & 0.1074 & 0.1509 & 0.1273 & 0.1074 & 0.3406 & 0.3924 & 0.3686 & 0.3406 & 0.1708 & 0.2226 & 0.1888 & 0.1708 \\
\hline
\end{tabular}




\section{RUSSIAN ELECTRONIC JOURNAL OF RADIOLOGY}

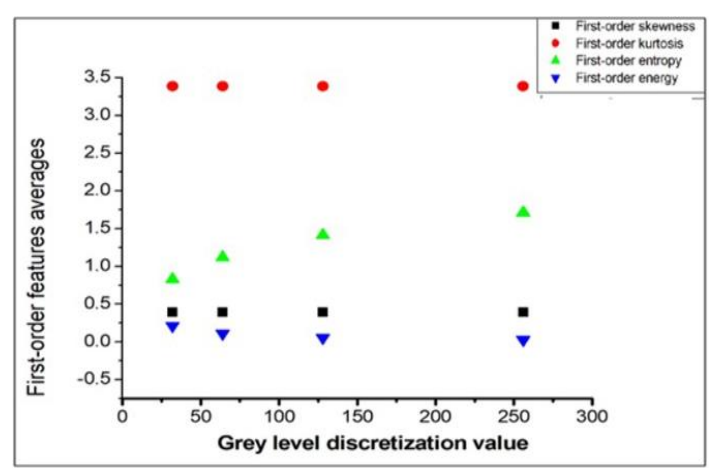

Fig. 3 (Рис. 3)

Fig. 3. The correlation of Grey level discretization value with first order radiomics features.

Рис. 3. Корреляция межАу значениями Аискретизации уровня серого с особенностями раАиомики.

the discretization value, the first order skewness and kurtosis were stable through the different discretization values where first order energy and entropy were variables.

In our previous work we studied the correla-

\section{References:}

1. Bradley W.G. Medical Imaging History. Proc. Am. Philos. Soc., 2015. 152 (3): 349-361.

2. O'Connor M.K., Kemp B.J. Single-Photon Emission Computed Tomography/Computed Tomography: Basic Instrumentation and Innovations. Semin. Nucl. Med., 2006. 36 (4): 258-266.

3. Lambin P., Rios-velazquez E., Leijenaar R. Radiomics: Extracting more information from medical images using advanced feature analysis. Eur. J. Cancer, 2012. 48 (4): 441-446.

4. Shafiq-Ul-Hassan M., Zhang G.G., Latifi K., Ullah G., Hunt D.C., Balagurunathan Y., Abdalah M.A., Schabath M.B., Goldgof D.G., Mackin D., Court L.E., Gillies R.J., Moros E.G. Intrinsic dependencies of $C T$ radiomic features on voxel size and number of gray levels. Med. Phys., 2017. 44 (3): 1050-1062.

5. Shafiq-Ul-Hassan M., Latifi K., Zhang G., Ullah G., Gillies R., Moros E. Voxel size and gray level normalization of $C T$ radiomic features in lung cancer. Sci. Rep., 2018. 8 (1): 1-9.

6. Altazi B.A., Zhang G.G., Fernandez D.C., Montejo M.E., Hunt D., Werner J., Biagioli M.C., Moros E.G. Reproducibility of F18FDG PET radiomic features for different cervical tumor segmentation methods, gray-level discretization, and reconstruction algorithms. J. Appl. Clin. Med. Phys., 2017. 18 (6): 32-48.

7. Van Velden F.H.P., Kramer G.M., Frings V., Nissen I.A., Mulder E.R., de Langen A.J., Hoekstra O.S., Smit E.F., Boellaard R. Repeatability of Radiomic Features in Non-Small-Cell Lung Cancer [18F]FDG-PET/CT Studies: Impact of Reconstruction and Delineation. Mol. Imaging Biol., 2016. 18 (5): 788-795.

8. Lu L., Lv W., Jiang J., Ma J., Feng Q., Rahmim A., Chen W. Robustness of Radiomic Features in [11C] Choline and [18F] FDG PET/CT Imaging of Nasopharyngeal Carcinoma: Impact of tion of radiomics features in liver cancer FDG/PET with tumor characteristics in both three dimensional and two dimensional mode $(3 \mathrm{D}$ and 2D) [13] so in this work we extended our work to study correlation between radiomics features and tumor characteristics at different discretization values.

Spearman rank correlation coefficient between radiomics features and tumor parameters (metabolic tumor volume, total lesion glycolysis, and maximum diameter) were determined as shown in table 2 . All features were variable expect first order skewness and kurtosis were found to be statistically stable among the different discretization values. The highest correlation between the tumor characteristics and occurred with discretization at value $=256$, the highest features were GLRLM_RLNU (Run Length Non-Uniformity) and NGLDM_Coarseness. Where the tumor kurtosis and GLZLM_LZE (Long-Zone Emphasis) showed a minimum correlation.

\section{Conclusion.}

When different PET discretization values applied to radiomics features of HCC PET images most features are variable, the highest correlation between the tumor characteristics occurred with discretization value 256 .

Segmentation and Discretization. Mol. Imaging Biol., 2016. 18 (6): 935-945.

9. Leijenaar R.T.H., Nalbantov G., Carvalho S., Van Elmpt W.J.C., Troost E.G.C., Boellaard R., Aerts H.J.W.L., Gillies R.J., Lambin P. The effect of SUV discretization in quantitative FDGPET Radiomics: The need for standardized methodology in tumor texture analysis. Sci. Rep., 2015. 5.

10. Brooks F.J., Grigsby P.W. The Effect of Small Tumor Volumes on Studies of Intratumoral Heterogeneity of Tracer Uptake. J. Nucl. Med., 2013. 55 (1): 37-42.

11. Mahmoud M.A., Shihab M., Saad S.S., Elhussiny F., Houseni $M$. Imaging differentiation of malignant hepatic tumors: radiomics and metabolic features of 18F-FDG PET/CT. REJR, 2021. 11(2): 165-170. DOI: 10.21569/2222-7415-2021-11-2-165-170. 12. Crandall J.P., Fraum T.J., Lee M., Jiang L., Grigsby P.W., Wahl R.L. Repeatability of 18 F-FDG PET Radiomic Features in Cervical Cancer. J. Nucl. Med. in press jnumed. 2020. 120, 247999.

13. Houseni M., Mahmoud M.A., Saad S., ElHussiny F, M.S. Advanced Intra-tumoral Structural Characterization of Hepatocellular carcinoma utilizing FDG-PET/CT: Comparative study of Radiomics and Metabolic features in $3 D$ and $2 D$. polish J. Radiol. 2021. 86: 64-73.

14. C Nioche, F Orlhac, S Boughdad, S Reuzé, J Goya-Outi, C Robert, C Pellot-Barakat, M Soussan, F Frouin, and I Buvat. LIFEx: a freeware for radiomic feature calculation in multimodality imaging to accelerate advances in the characterization of tumor heterogeneity. Cancer Research 2018; 78(16):4786-478. 